\title{
Application Research of Medical Failure Mode and Effect Analysis in Controlling Packaging Quality Defects
}

\section{Yanhua Chen (D 402888515@qq.com )}

West China Second University Hospital of Sichuan University

\section{Ruixue Hu}

West China Second University Hospital of Sichuan University

Juan Hu

West China Second University Hospital of Sichuan University

Wei Pan

West China Second University Hospital of Sichuan University

Liangying $\mathrm{Yi}$

West China Second University Hospital of Sichuan University

\section{Research Article}

Keywords: Packaging quality defects, Disinfection supply center, Medical failure mode and effect analysis, Risk management

Posted Date: September 16th, 2021

DOl: https://doi.org/10.21203/rs.3.rs-879722/v1

License: (c) (i) This work is licensed under a Creative Commons Attribution 4.0 International License. Read Full License 


\section{Abstract}

Purpose This study explores the application effects of medical failure mode and the analysis of device packaging quality defects.

Methods In this study, a total of 183,642 equipment kits were assembled in our hospital from January to June 2020. Using medical failure mode and effect analysis methods, we retrospectively analyzed and evaluated the device packaging process. Besides, we used a decision tree model to determine the strategies that need to be acted upon and formulate improvement plans. We also selected a total of $1,90,231$ assembly equipment packages in our hospital from July to December 2020, implemented the improved plan for packaging quality control, and compared medical failure modes, including the incidence of equipment packaging defects before and after the application of effective analysis.

Results Before implementing medical failure mode and effect analysis, 1,83,642 equipment packages were assembled, 98 defects occurred, with a defect rate of $0.053 \%$. However, after implementing medical failure mode and effect analysis to improve the packaging process, 1,90,231 device packages were assembled, 22 defects occurred, and the defect rate was $0.012 \%$. The results showed that the packaging quality defects of the disinfection supply center were significantly reduced $\left(X^{2}=50.822, P=0.001\right)$.

Conclusion Using the medical failure mode and effect analysis method to control device packaging defects can effectively reduce the rate of device packaging quality defects, ensuring patient safety.

\section{Introduction}

The disinfection supply center is the heart of the hospital's cleaning, disinfection, and sterilization, including the logistics center for the supply and turnover of sterile items. The quality of work directly affects the safety of medical care and patients, whereas equipment packaging quality defects waste the hospital workforce, material resources, and financial resources ${ }^{[1]}$. Based on reports, the defect rate in the packaging process accounts for $47.95 \%$ of the work quality defects in the disinfection supply center ${ }^{[2]}$. Therefore, the disinfection supply center faces an urgent problem in reducing the quality of equipment packaging defects. Health care failure mode and effect analysis (HFMEA) is a risk assessment and evaluation method recommended by the United States Joint Committee on Evaluation of Health Care Organizations in the medical field. It is a forward-looking and predictive risk management method that can be used to supervise high-risk nursing processes, identify and correct risk factors, and prevent mistakes in the first place ${ }^{[3-5]}$. At present, there are various ways to reduce the quality of equipment packaging defects, although most of them can be rectified. However, methods for proactive risk management analysis and propose corrective measures are still rare. Our department applies medical failure mode and effects analysis to control device packaging defects and achieves better results. The report is as follows:

\section{Material And Methods}




\subsection{General information}

A total of 3,73,873 instrument kits were selected as the research objects from January 2020 to December 2020.

\subsection{Methods}

\subsubsection{A total of $1,83,642$ equipment kits were selected from January to June 2020 as the control group.}

We used medical failure mode and effect analysis methods to analyze and evaluate the device packaging process retrospectively. Besides, the decision tree was used to identify the process for developing improvement plans.

We also selected 1,90,231 equipment kits to be assembled from July to December 2020 as the experimental group. We compared the incidence of device packaging defects before and after using medical failure mode and effect analysis by applying the improved solution for packaging quality control.

\subsubsection{The implementation process of medical failure mode and effect analysis}

\subsubsection{Choose high-risk processes and team formation}

Packaging is a complex process involving multiple steps, and packaging defects are the most critical issue. Nevertheless, packaging quality defects are high-risk processes via the analysis of department quality control data and team interviews. Thus, the HFMEA team was established: the head nurse of the department served as the supervisor; the head nurse served as the team leader; the rest of the staff completed the teamwork according to the division of labor.

\subsubsection{Sorting out the related processes of packaging quality defects}

The team members finally determined the primary approach of device packaging through discussion: unloading, inspection and assembly, verification, and packaging. Simultaneously, the sub-processes were also determined, shown in Figure 1. 


\subsubsection{Hazard analysis and decision tree analysis of device packaging process}

\subsection{List potential failure modes: The possible failure modes of the device packaging process were made based on the "brainstorming method."}

\subsection{Hazard Index (RPN) score}

We performed a hazard index (RPN) score for all listed failure modes. According to the theory of failure modes, severity $(S)$ and failure probability $(P)$ form a hazard index. The total score is 1-16 points. When the score is $\geq 8$ points, it is considered that this link will cause significant harm to the process and determined as a high-risk failure link ${ }^{[6-7]}$.

\subsection{Use decision tree analysis to determine whether to formulate improvement measures}

The identified high-risk failure links are further incorporated into the judgment decision tree analysis: "whether it is the only weakness," "whether effective control measures are formulated," "whether the danger can be detected." Finally, it has been decided to improve the functions of unchecked devices and loose device packaging ${ }^{[8]}$ (Table 1).

Table 1

Screening of high-risk links in failure modes of packaging quality defects 


\begin{tabular}{|c|c|c|c|c|c|c|}
\hline \multicolumn{2}{|l|}{ Process steps } & $\begin{array}{l}\text { Possible failure } \\
\text { mode }\end{array}$ & Severity & Incidence & RPN & $\begin{array}{l}\text { If the decision } \\
\text { (take action or } \\
\text { stop) index is } \\
\text { greater than } 8 \text {, } \\
\text { the action will } \\
\text { be stopped, } \\
\text { and the reason } \\
\text { should be } \\
\text { indicated }\end{array}$ \\
\hline \multirow[t]{3}{*}{ A Unloading } & \multirow[t]{3}{*}{ A1 Download } & $\begin{array}{l}\text { A1a Unloading } \\
\text { error }\end{array}$ & 1 & 4 & 4 & stop \\
\hline & & A1b Drop & 1 & 2 & 2 & stop \\
\hline & & A1c Omission & 1 & 1 & 1 & stop \\
\hline \multirow[t]{12}{*}{ B Inspection } & \multirow{4}{*}{$\begin{array}{l}\text { B1 Function } \\
\text { check }\end{array}$} & B1a Not checked & 4 & 4 & 16 & keep moving \\
\hline & & B1b Missed & 2 & $\cdot 2$ & 4 & stop \\
\hline & & B1c Misjudgment & 1 & 1 & 2 & stop \\
\hline & & $\begin{array}{l}\text { B1d Wrong } \\
\text { choice of } \\
\text { inspection } \\
\text { method }\end{array}$ & 2 & 3 & 6 & stop \\
\hline & \multirow{5}{*}{$\begin{array}{l}\text { B2 Cleaning } \\
\text { quality check }\end{array}$} & B2a Not checked & 1 & 4 & 4 & stop \\
\hline & & B2b Missed & 1 & 4 & 4 & stop \\
\hline & & B2c Misjudgment & 1 & 1 & 1 & stop \\
\hline & & $\begin{array}{l}\text { B2d Did not see } \\
\text { clearly }\end{array}$ & 2 & 3 & 6 & stop \\
\hline & & $\begin{array}{l}\text { B2e Wrong } \\
\text { choice of } \\
\text { inspection } \\
\text { method }\end{array}$ & 2 & 2 & 4 & stop \\
\hline & \multirow[t]{2}{*}{$\begin{array}{l}\text { B3 Quantity } \\
\text { check }\end{array}$} & B3a More & 4 & 4 & 16 & $\begin{array}{l}\text { stop (In the } \\
\text { future, } \\
\text { verification } \\
\text { and packaging } \\
\text { can be } \\
\text { eliminated) }\end{array}$ \\
\hline & & B3b Less & 4 & 4 & 16 & $\begin{array}{l}\text { stop (In the } \\
\text { future, } \\
\text { verification } \\
\text { and packaging } \\
\text { can be } \\
\text { eliminated) }\end{array}$ \\
\hline & $\begin{array}{l}\text { B4 Model } \\
\text { check }\end{array}$ & $\begin{array}{l}\text { B4a Model is } \\
\text { missing }\end{array}$ & 2 & 2 & 4 & stop \\
\hline
\end{tabular}




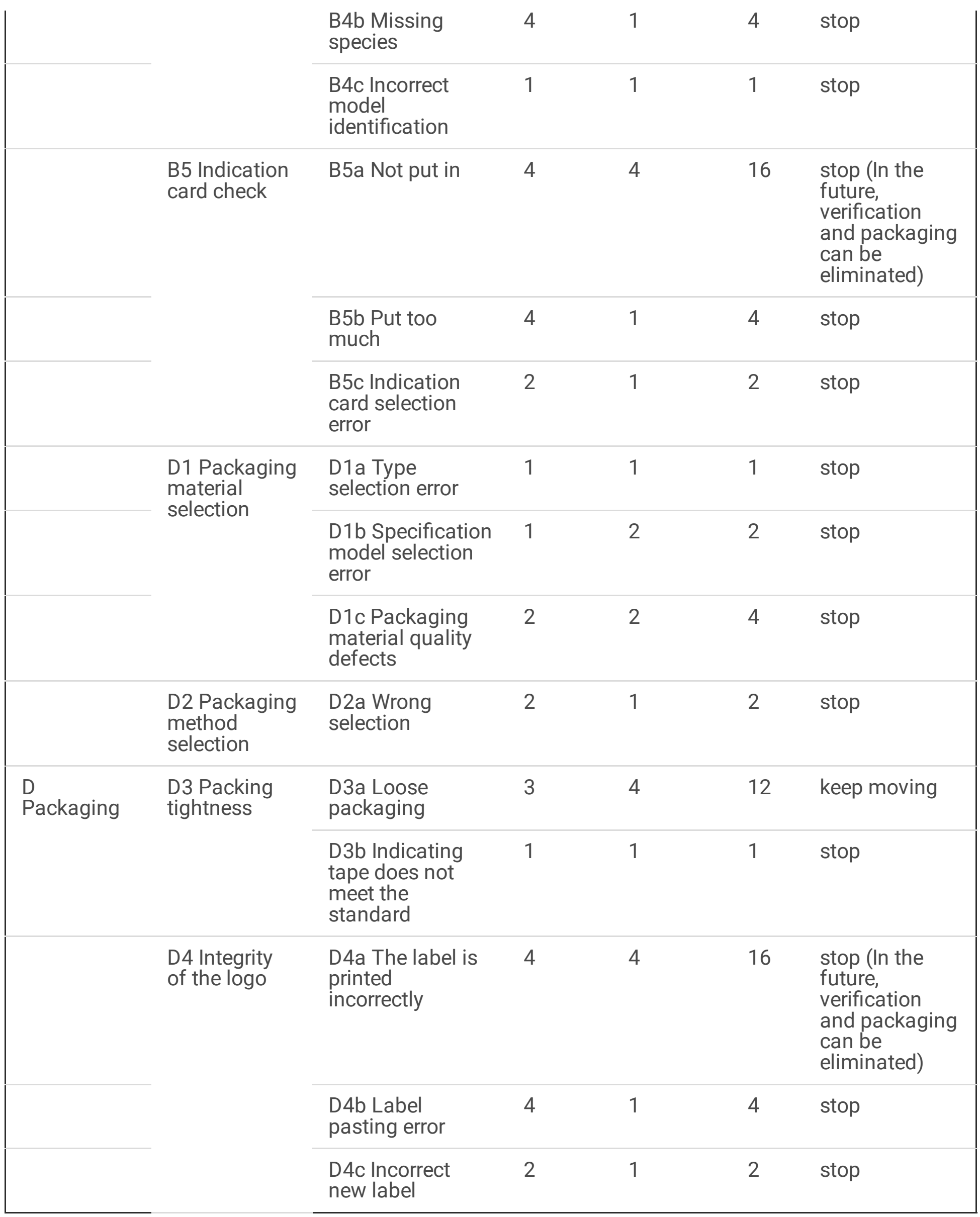




\subsubsection{Plan actions and measurements}

Using the characteristic factor diagram (fishbone diagram) to analyze the reasons for the unchecked device function and the loose device packaging, we found the root cause and formulated corresponding action strategies.

\subsection{Device function not checked}

(1) We altered the mode of nurse training to meet the needs of different nurse levels. The problemoriented PBL teaching model is used, and the training is done through situational exercises so that the nurses can master the relevant knowledge of the device function. Furthermore, assessments are performed before and after the training to evaluate the effectiveness of training. The PDCA cycle mode is used to continuously track the training effect and improve nurses' familiarity with professional knowledge about device functions ${ }^{[9]}$. (2) Produce SOP for functional inspections of various devices and map them. In turn, the inspection of the device function is more standardized and intuitive, and the staff compliance is improved. Simultaneously, all departmental staff must be aware of the importance of the functional status of commonly used surgical instruments to the operation and understand how to check the functions of various instruments ${ }^{[10]}$. (3) Increase the frequency of down collection four to six times. Simultaneously, increase the number of mobile personnel with flexible shifts according to the amount of surgery to prevent the phenomenon of unchecked functions caused by a large amount of equipment recovered in a short period. (4) Improve the inspection system for packaging positions and standardize inspection methods. Furthermore, the verification process is straightforward, including verification based on the exchange list before packaging, verification based on label details during packaging, strict doubleperson verification, and strict verification of label information outside the package and sealability after packaging.

\subsection{Loose device packaging}

(1) Disinfection supply center of the industry standard does not specify the length of the packet indicating tape, which is highly random. For this reason, after scientific proof, our department has designated catheterization kits, vaginal inspection kits, suture kits, etc., as small bags. The length of the packaging tape is $10 \mathrm{~cm}$ for one piece of package. The abortion package, cervical examination package, and the laparoscopy general equipment package are specified as medium packages. The length of the sealing tape is $12 \mathrm{~cm}$, and the number of packages is three. Fetal removal equipment, uterine equipment, bath towel bags, etc., are specified as large bags. The length of the packaging tape is $15 \mathrm{~cm}$, and the number of packages is four. When the packaging weight and volume exceed the industry standard, a corresponding tape should be added based on the actual situation. (2) The SOP for making specialshaped items packaging provides operators with standards to follow when assembling special-shaped items; the packaging process is improved further by reducing the occurrence of loose item packaging. 


\subsection{Statistical methods}

SPSS 17.0 statistical software was used for analysis, and the count data were analyzed using $\chi^{2}$ test. $\left.P\right]$ 0.05 indicates statistical significance.

\section{Results}

Table 2 presents a comparison of the device packaging quality defect rate before and after the implementation of medical failure mode and effect analysis.

Table 2

Comparison of the defect rate of the two groups of device packaging quality

\begin{tabular}{|lllll|}
\hline Groups & $\begin{array}{l}\text { Total number of } \\
\text { equipment packages }\end{array}$ & $\begin{array}{l}\text { Qualified number } \\
\text { of packaging }\end{array}$ & $\begin{array}{l}\text { Number of packaging } \\
\text { quality defects }\end{array}$ & $\begin{array}{l}\text { Defect } \\
\text { rate }\end{array}$ \\
\hline $\begin{array}{l}\text { Control } \\
\text { group }\end{array}$ & 183642 & 183544 & 98 & $0.053 \%$ \\
\hline $\begin{array}{l}\text { Experimental } \\
\text { group }\end{array}$ & 190231 & 190209 & 22 & $0.012 \%$ \\
\hline$\chi^{2}=50.822 ; P=0.001$ & & & \\
\hline
\end{tabular}

After implementing the medical failure mode and effect analysis, the device packaging defects were significantly reduced, which is statistically significant, shown in Table 2.

\section{Discussion}

\subsection{Risk assessment and analysis of device packaging}

Figure 1 depicts the main process of equipment packaging after the team members have jointly confirmed it: unloading, inspection and assembly, verification, and packaging. Simultaneously, the main process is divided into sub-processes. Besides, the team members list all possible failure modes for each sub-process and calculate the hazard index based on the severity of failure mode and frequency with which it can occur. For the hazard index $\geq 8$ points, more action is required. According to Table 1 , the hazard index of four steps is more than 8; namely, instrument function unchecked, a small number of instruments, a large number of instruments, and loose instrument packaging. Thus, these four steps need to be analyzed.

\subsection{Analysis of decision-making actions}

The HFMEA decision tree indicates three issues: if the failure mode and step will cause significant damage to the system; if this item is the only weakness or key in the entire process; if there is no effective 
measure to control the occurrence of the failure mode, the appropriate actions must be taken. In both the device verification and packaging, an insufficient number of devices and a large number of devices have corresponding inspection systems that can effectively prevent incidents. However, there is no effective way to control this failure mode if the device function is not checked and device packaging is loose. Therefore, the actual cause of device packaging process failure is that the device function is not being checked, or the device packaging is loose; thus, appropriate measures are taken to address the problem.

\subsection{Analysis of the decline in the quality defect rate of device packaging}

The results presented in Table 2 show that after the implementation of medical failure mode and effect analysis management, the device packaging quality defect rate has dropped from $0.053-0.012 \%$. This research first sorts out the device packaging process and decomposes the primary process and subprocesses to clarify the entire process. Subsequently, the hazard analysis was performed in the medical failure mode using the hazard score matrix and effect analysis. The primary reasons for the quality defects of the device packaging were also found. The project team developed various intervention plans based on critical factors, improved the device packaging process, and more standardized the behavior of device packaging personnel. The analysis of medical failure modes and their effects are focused on prevention. Based on the early prediction of relevant risk factors, targeted and comprehensive nursing measures are developed to improve deficiencies in previous operations and improve the level of operation, thereby preventing the occurrence of operational risk events ${ }^{[11-14]}$. During the analysis, it was discovered that when the device was packaged, the function of the device was not tested, and the device packaging was loose, posing significant hidden risks to the entire device packaging process. Therefore, it is necessary to strengthen the management of related links to reduce packaging quality defects. As the actual executor, if the operator makes an error in the packaging of the device, it is usually attributed to a personal mistake or behavioral error. However, it is not difficult to find that most errors are caused by behavioral deviations caused by imperfect processes or systems, accounting for about $70 \%$ of the total [15-16]. Therefore, after using the medical failure mode and effect analysis, the manager modified his previous practice in attributing errors to the operator. Instead, it examines all aspects of the entire device packaging process by producing various device functional inspection SOP, particular device packaging SOP, packaging standards for various sterile packages, and a complete inspection system. Finally, optimizing the device packaging process reduces packaging quality defects and effectively improves the packaging quality of medical devices to ensure surgical safety for patients ${ }^{[17]}$.

\section{Conclusion}

In the current work of the disinfection supply center, packaging quality defects are a key issue in post work. The previous data shows that tools such as FMEA can perform a detailed analysis of the complex packaging process, outline potential failure modes, and emphasize which risks are most worrying to 
guide improvement efforts and focus on high-risk tasks. In addition, this study is a single-center study, with a short data collection time and short observation time after the experiment. We hope that the data used here can be expanded, and the observation time can be extended further to evaluate the effect of the investigation in the future.

\section{Declarations}

\section{Ethics approval and consent to participate}

This study was conducted in accordance with the Declaration of Helsinki, and this study was approved by the Medical Ethics Committee of West China Second University Hospital, Sichuan University. The Medical Ethics Committee of West China Second University Hospital, Sichuan University reviewed and approved the research proposal and procedure of verbal consent of this study, and felt that it was not necessary to obtain written consent from participants. All data collected were confidential and used only by this study.

\section{Consent for publication}

Not applicable

\section{Availability of data and materials}

The datasets used and/or analysed during the current study are available from the corresponding authors on reasonable request.

\section{Competing interests}

The authors declare that they have no competing interests.

\section{Author details}

${ }^{1}$ Central Sterile Supply Department, West China Second University Hospital, Sichuan University/West China School of Nursing, Sichuan University, Chengdu, Sichuan, China

${ }^{2}$ Key Laboratory of Birth Defects and Related Diseases of Women and Children (Sichuan University), Ministry of Education, Chengdu, Sichuan, China

\section{Funding}




\section{Authors' contributions}

$\mathrm{YC}$ and $\mathrm{JH}$ contributed to the study design. YC and WPconducted the data collection. RH conducted the data analysis. YC and LY drafted the manuscript. JH revised the manuscript. All the authors read and approved the final manuscript.

\section{Acknowledgements}

The authors would like to thank the nurses and workers working in the central sterile supply department of the West China Second Hospital, Sichuan University.

\section{References}

1. Zhang Dingjie, Huang Yujie, Ruan Yiman. Application of quality control circle in improving cleaning quality of disinfection supply center [J].International Journal of Nursing,2018,37(1):122-124.

2. Fang Ling, Chen Ying, Wang Jing, Liu Lei, Li Jing, Yuan Yuan, Chen Lili, Hu Yan. Practice of " four modernizations" measures in the on-the-job training of packaging service: effect evaluation[J].Journal of Nursing Science,2013,28(09):51-52.

3. Devarakonda S.Application of healthcare failure mode and ef-feet analysis in improving patients education at an outpatient department at a tertiary care hospital[J].Value in Health,2016,19(7): 831.

4. Blackmore, C. C., et al.Applying lean methods to improve quality and safety in surgical sterile instrument processing. Jt Comm J Qual Patient Saf 2013,39(3): 99-105.

5. Haynes AB, Weiser TG, Berry WR, Lipsitz SR, Breizat AH, Dellinger EP, et al. A surgical safety checklist to reduce morbidity and mortality in a global population. N Engl J Med. 2009;360(5):491-499. doi: 10.1056/NEJMsa0810119.

6. Cheng Lan, Sun Niuyun, Wang Li. Comparative Analyses on Methods and Tools for Medical Risk Management and Assessment in the United Kingdom, the United States, Canada, Australia and Taiwan Region[J].Chinese Journal of Evidence-Based Medicine, 2011, 11(11):1240-1246.

7. Lei Jun, Pang Jun, Ju Lin. Analysis of Quality Management of Disinfection and Sterilization in Hospital Supply Room [J].Chinese Journal of Disinfection,2016,33(11):1137-1138.

8. Tian Fengmei, Zhang Xiaoyan, Lu Yaqiong, Xiao Aihua. Application of healthcare failure mode and effect analysis of hyperglycemia management in hospitalized diabetic patients[J].Chinese Journal of Nursing,2018,53(03):305-309.

9. Sun Liyan, Liu Yijing. Application effects of healthcare failure mode and effect analysis in preventing adverse events of elderly patients[J].Journal of Nursing Administration,2013,13(1):42-43. 
10. Li Fuxuan, Bai Xiaoxia, Cao Min. Using failure mode and effect analysis to transform the processing flow of endoscopic instruments [J].Journal of Nurses Training,2011,26(17):1562-1564.

11. Jiang Yuan, Cao Xiaolei. Application effect of medical failure mode and effect analysis in preventing infection of hemodialysis patients and improving nursing satisfaction [J].International Journal of Nursing,2018,37(23):3300-3302.

12. Ryckman FC, Schoettker PJ, Hays KR, Connelly BL, Blacklidge RL, Bedinghaus CA, et al. Reducing surgical site infections at a pediatric academic medical center. Jt Comm J Qual Patient Saf. 2009;35(4):192-198. doi:10.1016/S1553-7250(09)35026-6.

13. Kable AK, Gibberd RW, Spigelman AD. Adverse events in surgical patients in Australia. Int $\mathrm{J}$ Qual Health Care. 2002;14(4):269-276. doi: 10.1093/intqhc/14.4.269.

14. Gawande AA, Thomas EJ, Zinner MJ, Brennan TA. The incidence and nature of surgical adverse events in Colorado and Utah in 1992. Surgery. 1999;126(1):66-75. doi: 10.1067/msy.1999.98664.

15. Thomas EJ, Studdert DM, Burstin HR, et al. Incidence and types of adverse events and negligent care in Utah and Colorado [J]. Med Care, 2000,38(3): 261-271.

16. Xu Yinhua, Sang Yimao, Yu Hui, Xu Hongwen. Study of the application of health failure mode and effect analysis in nursing management of operating room[J].Chinese Journal of Modern Nursing,2018,24(13):1609-1612.

17. Cai Xuejiao, Li Tianyi, Cheng Ping. Research on the application effect of the improvement plan for the packaging of foreign medical devices [J].Chinese Journal of Disinfection,2018,35(04):305-306.

\section{Figures}

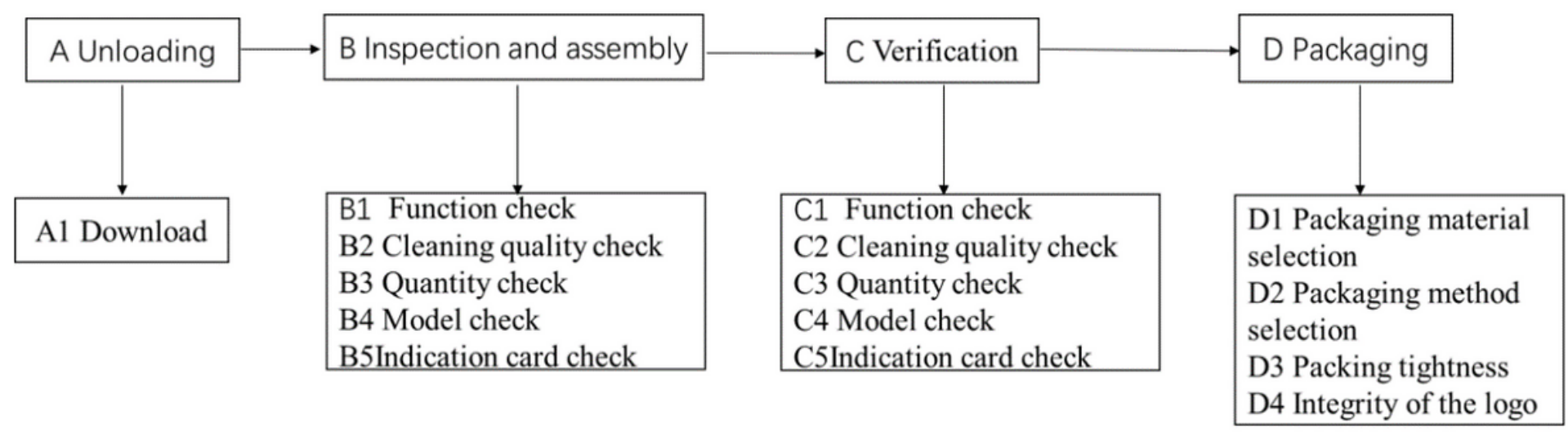

\section{Figure 1}

Exploded diagram of the packaging process 